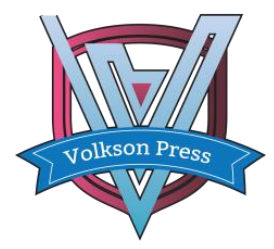

Contents List available at VOLKSON PRESS

Mechanical and Control Engineering (MCE)

DOI : http://doi.org/10.26480/wsmce.01.2017.37.38

\title{
RESEARCH AND DEVELOPMENT OF DURABILITY TEST DEVICE FOR RAIL PASSENGER CAR LOCKS
}

\author{
Li Zihua, Cao Yu* \\ China Railway Test \& Certification Centre, Jiuxianqiao North Road 1, Beijing, China \\ *Corresponding Author Email: chycrcc@163.com
}

This is an open access article distributed under the Creative Commons Attribution License, which permits unrestricted use, distribution, and reproduction in any medium, provided the original work is properly cited

\section{ARTICLE DETAILS}

\section{Article History:}

Received 02 october 2017

Accepted 06 october 2017

Available online 11 november 2017

Keywords:

Test device, rail passenger car

locks, durability test

\section{ABSTRACT}

As the development of China's high-speed railway, the production of rail cars, locomotives, as well as the components, such as rail passenger car locks, increased significantly. It is vital that their operation is reliable, which is related to the safety of the whole railway system. A new durability test device for rail passenger car locks is researched and developed in this paper, with which the durability test of rail passenger car locks can be carried out automatically. Practicality of this device is validated, and it turns out that the device is compact, highly efficient, suitable for various types of locks and is of simple operation.

\section{Introduction}

As the development of China's high-speed railway in recent years, the production of rail cars, locomotives increased significantly, as well as the production of components on them such as locks increased at the same time [1]. It is vital that their operation is reliable, which is related to the safety of the railway system. There are various types of rail passenger car locks with different structures. In addition, China Railway Corporation issued a series of standards e.g. the Q/CR 499, TJ/CL 443, TJ/CL 444, etc. in which the test requirements of rail passenger car locks are stated. Therefore, it is very important to that rail passenger car locks are tested according to the standards [2].

The frequency, and the cycles of durability test of rail passenger car locks are specifically required in the mentioned standards, for instance, the cycles range from thousands to tens of thousands. The most common way of the test is manually operated, which is of low reliability, low efficiency and high labor cost. At present, there are few devices that are designed for the durability test of rail passenger car locks and the existing device is often built for one specific type of lock. Therefore, in order to improve the efficiency of the test and save labor cost, it is urgent to study the durability test device for rail passenger car locks.

\section{THE DURABILITY TEST REQUIREMENTS IN STANDARDS}

The requirements of durability test for rail passenger car in aforementioned standards are shown in the Table 1.

Table 1: Requirements of Durability Test

\begin{tabular}{lll}
\hline Standards & Cycles of test & Frequency/min-1 \\
\hline Q/CR 499 & $1 \times 10^{5}$ & $\leq 30$ \\
TB/T 1760 & $1 \times 10^{5}$ & $\leq 30$ \\
TJ/CL 443 & $4.8 \times 10^{4}$ & $\leq 30$ \\
TJ/CL 444 & $4.8 \times 10^{4}$ & $\leq 30$ \\
\hline
\end{tabular}

According to these test requirements, a new durability test device for rail passenger car locks is developed.

\section{DESIGN SCHEME}

\subsection{Structural design}

The durability test device for rail passenger car locks consists of 3 parts: test desk, specimen fixture and control box. The specimen fixture and control box are mounted on the test desk. The control box consists of shell, touch screen, bearing housing, step motor, AC/DC module, PLC, step motor driver, position sensors, output shafts, gear housing, position sensor support, drive gear, motor gear and positioning rod.

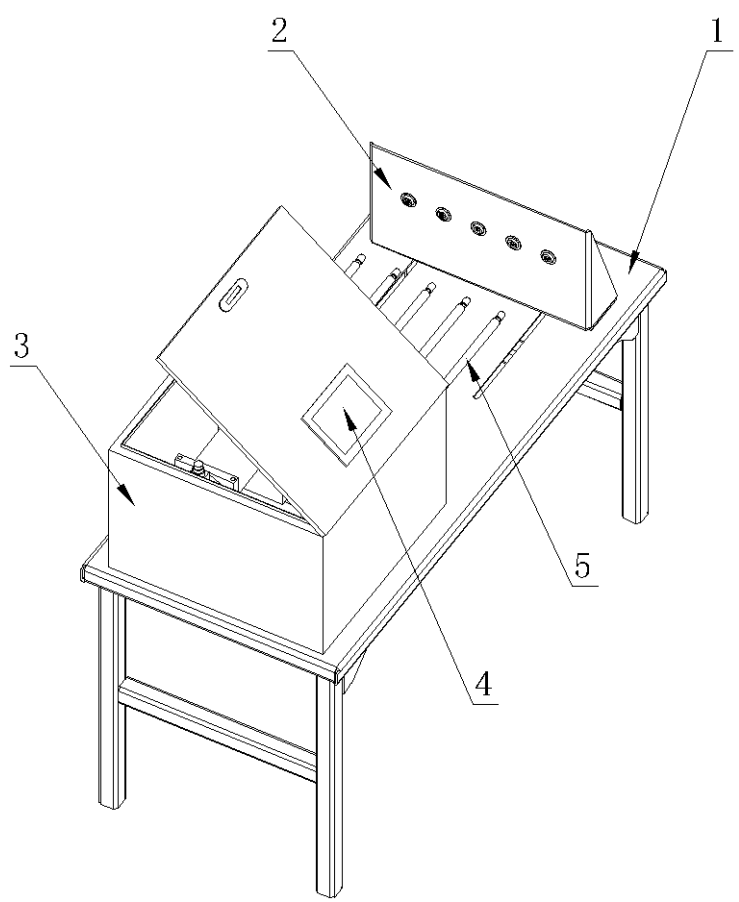

a. Isometric View 


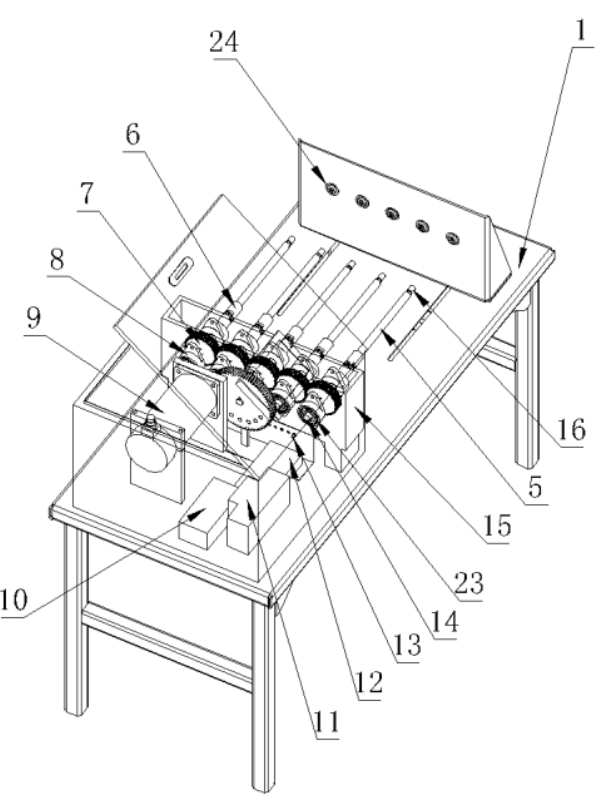

b. Transparent View

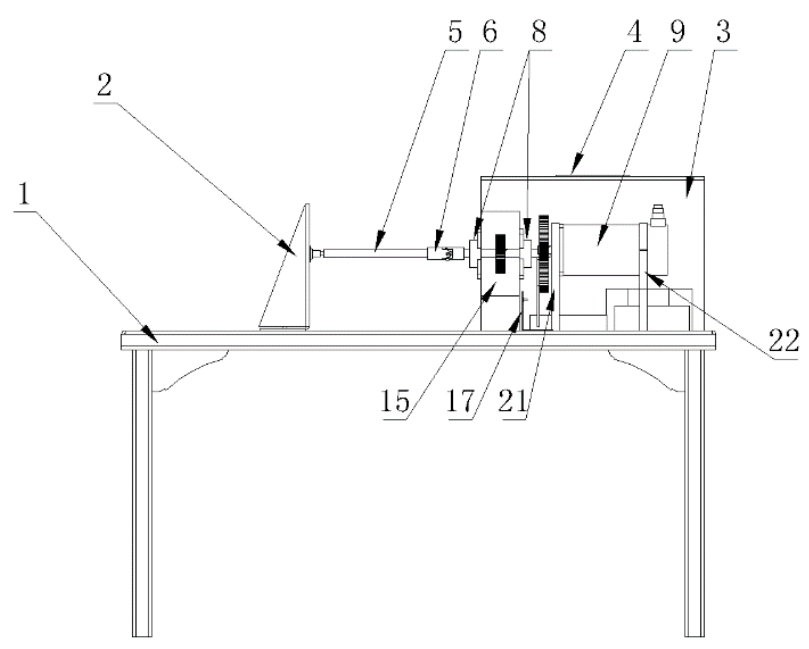

c. Front View

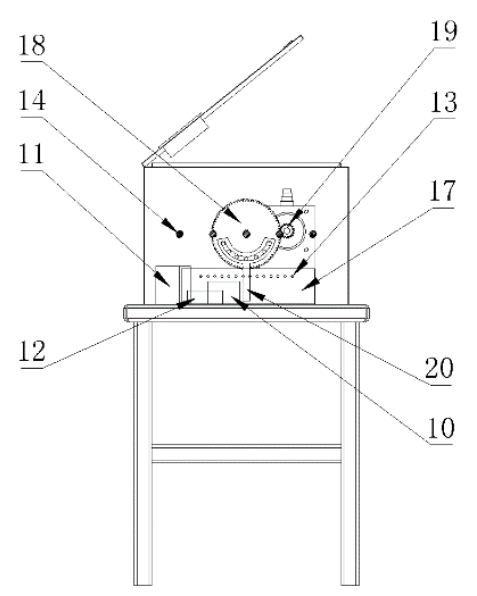

d. Cutaway View

1-Test desk, 2-Specimen fixture, 3-Shell, 4-Touch screen, 5-Actuator rod, 6-Ball joint, 7-Transmission gear, 8-Bearing housing, 9-Step motor, 10AC/DC module, 11-PLC, 12-Step motor driver, 13-Position sensor, 14Output shaft, 15-Gear housing, 16-Key, 17-Position sensor support, 18Drive gear, 19-Motor gear, 20-Positioning rod, 21-Motor bracket(front), 22-Motor bracket(rear), 23-Bearing, 24-Specimen
As shown in Figure 1, the specimen fixture is bolted in the slot on the test desk, and its position can be adjusted along the slot. The touch screen is embedded on the top of the control box shell, and is connected with the PLC. The AC/DC module supplies power to the screen and the step motor driver. The step motor is supported by the front and the rear brackets, which are bolted on the test desk. Motor gear is mounted on the output shaft of the motor, and the motor gear meshes with the drive gear. The positioning rod is bolted on the drive gear. There are several screw holes on the drive gear, where the positioning rod can be bolted alternatively, according to specific test requirements.

\subsection{Technical characteristics}

There are three main advantages of this durability test device for rail passenger car locks:

1. It is compact, highly efficient, suitable for various types of locks and is of simple operation, and up to five specimens can be tested at the same time.

2. Most parts of this device can be reassembled flexibly, according to different test requirements.

3. With the touch screen, the parameters of the test such as the motor speed, the number of cycles and frequency can be set individually. The process of the durability test can be easily monitored with the screen, which is highly labor-saving.

\section{OPERATION PRINCIPLES}

To achieve the aforementioned functions, the durability test device for rail passenger car locks is researched and developed and shown in Figure 1. Before the test, the specimens should be installed on the specimen fixture, the position can be adjusted along the slot so that the keys can be inserted into the locks. Set the test parameters on the touch screen after powered on.

After the parameter setting is confirmed, start the test on the screen. The PLC is programmed to control the motor driver, and the driver drives the step motor to rotate, and the motor gear starts to drive the drive gear and transmission shaft. So the transmission gears as well as the output shafts are driven by the transmission shaft. And the actuator rods are driven through the output shafts, with which actuator rods are ball jointed. The keys are mounted at the end of the actuator rods, thus locks are driven by the keys [3].

The positioning rod moves as the drive gear rotates, and the positioning sensors are triggered by the positioning rod. The PLC controls the motor driver to make the motor rotate clockwise or counterclockwise when received the positioning sensor signals. The keys and the specimen fixture are removable and can be changed when the types and structures of the specimen locks are different [4].

\section{CONCLUSION}

A new durability test device for rail passenger car locks is developed. Practicality of the device is validated by a type of rail passenger car lock. The number of cycles is 48,000 , and the process of the durability test meets the requirements of the corresponding standard. With this new device, the durability test of rail passenger car locks can be carried out automatically, and it turns out that the device is highly efficient, suitable for various types of locks and is of simple operation.

\section{REFERENCES}

[1] Huawu, H. 2007. Development and Technical Innovation of China Railway. Journal of Railway Engineering Society, 24 (7), 1-11.

[2] Wei, J. 2015. Discussion on Risk Control of Product Inspection for Railway Product Certification. Railway Quality Control, 12 (5), 23-24.

[3] Xiahe, L., Rencheng, Z., Zhongshan, C. 2011. Development of MultiChannel Locks Performance Testing System. Journal of Huaqiao University (Natural Science), 32 (1), 18-21.

[4] Genzhong, Z., Fan, T. 2011. Design of a door lock life testing machine in accordance with American standards. Hardware Science and Technology, 39 (3), 74-76.

Figure 1: Device Structure 